\title{
Dehydroepiandrosterone, Over-studied but Under-used in the Treatment of Vascular Remodeling Diseases
}

\section{Roxane Paulin and Sébastien Bonnet*}

Department of Medicine, Laval University, Centre de Recherche du CHUQ, Hôtel-Dieu de Québec, Québec City, QC, Canada

\begin{abstract}
Vascular remodeling is characterized by a narrowing of the lumen of the vessels, resulting in decreased blood flow, increased pressure and heart failure. This process is found in diseases like atherosclerosis, restenosis after angioplasty, transplants coronary disease, systemic and pulmonary hypertensive vascular disease, and is stimulated by elevated levels of cholesterol, inflammation, oxidative stress, excess of vasodilating molecules and growth factors. Efficient treatments able to fix or prevent the progression of this process are still missing. The hormone dehydroepiandrosterone (DHEA), which levels decrease with aging while cardiovascular risks increase, was hypothesized to have a role in the pathophysiology of vascular diseases. Despite the fact that numerous properties such as fat-reducing, anti-oxidant, vasodilating, anti-inflammatory and anti-proliferative have emerged from two decade of studies, DHEA remain clinically underused in the treatment of vascular remodeling diseases. The lack of understanding of the exact mechanism of action and some controversial epidemiological studies are not foreign to the fact that DHEA is shunned. Nonetheless, we believe that DHEA cannot be ignored since promising results were obtained pre-clinically and clinically in the treatment of vascular remodeling diseases. We are probably close to understand the function of this molecule, especially by its action as a peroxisome proliferator, and it will be a shame to deprive patient of a way to improve their quality of life, or worst a way to extend their survival.
\end{abstract}

\section{Introduction}

Inward inappropriate vascular remodeling is a common feature of several diseases like atherosclerosis, restenosis after angioplasty, transplants coronary disease, systemic and pulmonary hypertensive vascular disease [1] causing a narrowing of the lumen and decreasing maximal flow rates. The arterial wall is composed of three independent layers: a monolayer of endothelial cells (ECs) called intima, a main layer composed by vascular smooth muscle cells (VSMCs), the media, and a network of connective tissue, the adventitia. Under physiological conditions, VSMCs are quiescent, contractile and non-migratory. Remodeling occurs in response to various stimuli that disrupt the usually ordered multilayered structure of the wall by activating VSMCs. Elevated cholesterol levels, inflammation, oxidative stress, excess of vasodilating molecules and growth factor are potent stimuli that are found in these diseases. Most of these molecules bind receptors and enhance cascades of signal transduction resulting in a pro-proliferative, survival, constricted, migratory and invasive phenotype of the VSMCs. This abnormal VSMC's phenotype plays a critical role in the thickening of vessel wall, the rearrangements of cellular and non-cellular elements and/or the formation of neointima or atherosclerotic plaque.

Dehydroepiandrosterone (DHEA) is an adrenal steroid circulating abundantly as a sulfate conjugated form DHEA-S [2]. DHEA-S reaches a maximal plasma level between 15 and 25 years old and the following decline in DHEA-S [3-5] has been related to aging-associated diseases development [6-10]. DHEA is a potent uncompetitive inhibitor of the first enzyme in the pentose phosphate pathway (PPP), the mammalian glucose-6-phosphate deshydrogenase (G6PDH). Studies performed on Sardinian males bearing a Mediterranean variant of G6PDH deficiency, support the hypothesis that reduced G6PDH activity has a beneficial affect on age-related disease development. Indeed, these individuals arbor reduced mortality rates from cerebrovascular and cardiovascular diseases and seems to be more likely to achieve centenarian [11]. Since almost a century, numerous hypothesis have emerged on the possible role of DHEA(-S) in the pathophysiology of vascular diseases, especially coronary heart diseases, atherosclerosis, carotid stenosis and Pulmonary Hypertension. Number of studies using DHEA as therapy exploded at the end of the eighties. These studies, while showing an efficient impact of DHEA in the reduction of remodeling processes [1214], failed to demonstrate the exact mechanism by which the molecule act. Hormone replacement therapy using DHEA and DHEA-S in elderly has even been discussed [10,15-17] without concretization. The original enthusiasm has been replaced by sober skepticism, as many questions remain unanswered. Moreover epidemiologic studies were controversial concerning the hypothesis of an inverse correlation between the diseases manifestation and the serum level of DHEA(S), and showed dramatic differences according to sex and diseases end-point for example [18-21]. Close to two decades after, without clarification of the exact mechanism of action of the molecule, several properties of DHEA such as fat-reducing, anti-oxidant, vasodilating, anti-inflammatory and anti-proliferative properties have emerged, increasing again the interest for the treatment of cardiovascular diseases. We propose in this review to make an overview of the findings supporting the fact that DHEA could be an important therapeutic strategy in the treatment of vascular diseases, explaining how DHEA can works and to discuss why DHEA remain clinically underused as therapy.

*Corresponding author: Dr. Sébastien Bonnet, Centre de Recherche de L'HôtelDieu de Québec, 10 rue McMahon, Québec, QC, G1R2J6, Canada, Tel: 418525 4444; Fax: 418-691-5562; E-mail: sebastien.bonnet@crhdq.ulaval.ca

Received November 02, 2011; Accepted December 03, 2011; Published December 06, 2011

Citation: Paulin R, Bonnet S (2011) Dehydroepiandrosterone, Over-studied but Under-used in the Treatment of Vascular Remodeling Diseases. J Steroids Hormon Sci S3:001. doi:10.4172/2157-7536.S3-001

Copyright: (C 2011 Paulin R, et al. This is an open-access article distributed under the terms of the Creative Commons Attribution License, which permits unrestricted use, distribution, and reproduction in any medium, provided the original author and source are credited. 


\section{DHEA Cholesterol/Fat Reducing Properties}

Low-density lipoproteins (LDL), also called bad cholesterol, are known to promote cardiovascular diseases and particularly atherosclerosis. This syndrome begins by damage to the endothelium leading to a chronic inflammatory response in the walls of arteries by expression of various adhesion molecules and cytokines, which promote the migration of circulating leukocytes, such as monocytes, $\mathrm{T}$ lymphocytes and dendrites into the sub-endothelial space of the artery [22]. Oxidized-LDL are implicated in the initiation of inflammatory processes [23] as migrating mononuclear leukocytes incorporate oxidized-LDL to become foam cells, which accumulate in the subendothelial space due to an impaired emigration. Foam cells secrete oxygen-free radicals as well as various cytokines that further accelerate inflammation [24-26]. VSMCs migrate into the neointima and secrete matrix proteins to stabilize the plaque [27-29]. Instability in the cap may lead to rupture and subsequent thrombus formation.

In humans and rodents, DHEA administration have been described to result in a substantial decrease in body fat mass, fat accumulation and decreased body weight [30-34]. As a G6PDH inhibitor, DHEA inhibits the production of NADP [35]. NADPH is involved in numerous metabolic pathways such as fatty acid, phospholipid, cholesterol and steroid synthesis and its reduced production lead to decreased fatty acid production and subsequent reduction of LDL production. In these conditions, less LDL can be oxidized and fewer atheromas would be formed [36]. Indeed, DHEA has been found to have an inhibitory effect on cholesterol ester accumulation induced by AcLDL in cultured macrophage cells (5774-1 cells) [37], but the mechanism was poorly understood.

DHEA is known as a peroxisome proliferator able to induce many genes through peroxisome proliferator-activated receptors (PPAR) [38]. Once activated, the isoform PPARa represses activation of enzymes involved in fat synthesis $[39,40]$. DHEA can be implicated in lowers triglycerides production and in less fat deposition through its effect on PPARa. In adipose tissue the predominant isoform of PPAR is PPAR $\gamma$, a nuclear hormone receptor and a ligand-activated transcription factor that binds specifically to PPAR response elements in the promoter regions of target genes and regulates the transcription of many adipocyte-specific genes [41,42]. DHEA has been shown to induce PPAR $\gamma$ gene expression by over 2.5 -fold in adipose tissue of DHEA-treated rats. DHEA-induced PPAR $\gamma$ activation may lead to an increase in lipolysis rate, increased flux of fatty acids through the $\beta$-oxidation pathway and a decrease in de novo lipogenesis rate in adipose tissue, accompanied by an increase in energy expenditure [43].

\section{DHEA Anti-oxidant and Anti-inflammatory Properties}

Another recent study hypothesized that DHEA may affect the oxidized LDL-induced inflammatory response. Indeed, DHEA administration was shown to modulate the expression of inflammatory molecules in human umbilical vein endothelial cells (HUVECs) injured by oxidized LDL, like up-regulating nitric oxide production and down-regulating malondialdehyde, adhesion molecules VCAM1, ICAM and E-selectin. This was attributed in part to a DHEAdependant inhibition of NF- $\kappa B$ and a subsequent attenuation of inflammation [44]. Indeed, multiple genes involved in monocyte/ endothelial interaction such as vascular cell adhesion molecule-1 (VCAM-1) and monocyte chemotactic protein-1 (MCP-1) contain in their promoters NF- $\mathrm{kB}$ binding sites [45]. DHEA-dependant inhibition of NF- $\kappa B$ is not surprising considering the fact that PPAR $\alpha$ has been shown to antagonize NF- $\kappa$ B signaling pathway involved in the vascular inflammation of atherosclerosis $[46,47]$. This hypothesis was formulated by Altman et al. whom showed that DHEA(-S)-dependant VCAM-1 decreased expression could be partially restored by using the PPARa inhibitor MK866 [48]. These findings furnish important clues on DHEA mechanism of actions and demonstrate a significant role for DHEA(-S) in the prevention of inflammatory processes in the endothelium.

\section{DHEA Vasodilating Properties}

A constricted state of VSMCs in wall arteries is also a factor increasing the inward narrowing of the vessels. In pulmonary arterial hypertension $(\mathrm{PAH})$, distal arteries are particularly constricted and this phenomenon plays a critical role in the global rise of pressure observed in the pulmonary vasculature. Several mechanisms are implicated in this abnormal constricted state. First, an imbalance between vasoconstricting and vasodilating factors levels have been measured in the serum of PAH patients [49-51], with an abnormal downregulation of vasodilating molecules like nitric oxide and an overexpression of vasoconstricting molecules like endothelin-1 [52-54]. There are also evidences showing a decrease in gene expression and function of $\mathrm{K}_{\mathrm{v}}$ channels [55] as well as a decrease in $\mathrm{BK}_{\mathrm{Ca}}$ protein expression [56] resulting in membrane depolarization and enhanced contraction.

Ratios of cellular reducing factor, such as $\mathrm{NADP}^{+} / \mathrm{NADPH}$ and GSH/GSSG are known to open $\mathrm{Kv}$ and $\mathrm{BK}_{\mathrm{Ca}}$ channels and hyperpolarize plasma membrane [57-59]. Following this principle, again as an inhibitor of the PPP and able to modify these ratio (Figure 1), DHEA was hypothesized to have vasodilating properties. DHEA was found to efficiently inhibit hypoxic pulmonary vasoconstriction, at least in part by opening $\mathrm{BK}_{\mathrm{Ca}}$ channels in pulmonary VSMCs [60-62]. Western Blot analysis of arterial pulmonary extract showed that the $\mathrm{BK}_{\mathrm{Ca}}$ subunit expression is upregulated after DHEA treatment compared to chronic hypoxia rats [63]. By using specific $\mathrm{K}^{+}$channel inhibitors, it was identified that only $\mathrm{K}_{v}$ channels are positively implicated in DHEA-dependent relaxation of VSMCs. DHEA also prevents and reverses chronic hypoxia induced pulmonary hypertension in rats by $\mathrm{BK}_{\mathrm{Ca}}$ opening.

Vascular tone is also controled by cyclic guanosine 3', 5 '-monophosphate (cGMP), a factor generated in the vasculature via two main guanylate cyclase: cytosolic soluble guanylate cyclase (sGS) and membrane-bound particulate guanylate cyclase (pGC) [64]. sGC serves as a receptor for biologically active gas nitric oxide (NO) $[65,66]$ and cGMP is generated by sGC following this interaction. DHEA has been reported to increase sGC protein expression and activity and by improving pulmonary artery vasodilator responsiveness to NO [67]. DHEA effects on sGC may not be direct but again, secondary to PPP inhibition and increased levels $\mathrm{H}_{2} \mathrm{O}_{2}$ production that have been reported to stimulate sGC and increase cGMP in vasculature $[68,69]$. Finally, activation of the RhoA/ROCK signaling pathway contributes to vasoconstriction in VSMCs, a pathway that plays an important role in the pathogenesis of PAH. Chronic DHEA treatments in PAH rat model were described to decrease RhoA/ROCK signaling pathway activity by multiple mechanisms, including preservation of sGC expression and inhibition of ROCK cleavage [70].

\section{DHEA Anti-proliferative Properties}

In diseases like restenosis and $\mathrm{PAH}$, the proliferative phenotype of VSMCs is critical in the inward narrowing of the vessel. Some enzymes, essential for cell cycle progression like multifunctional $\mathrm{Ca}^{2+} / \mathrm{CaM}-$ 


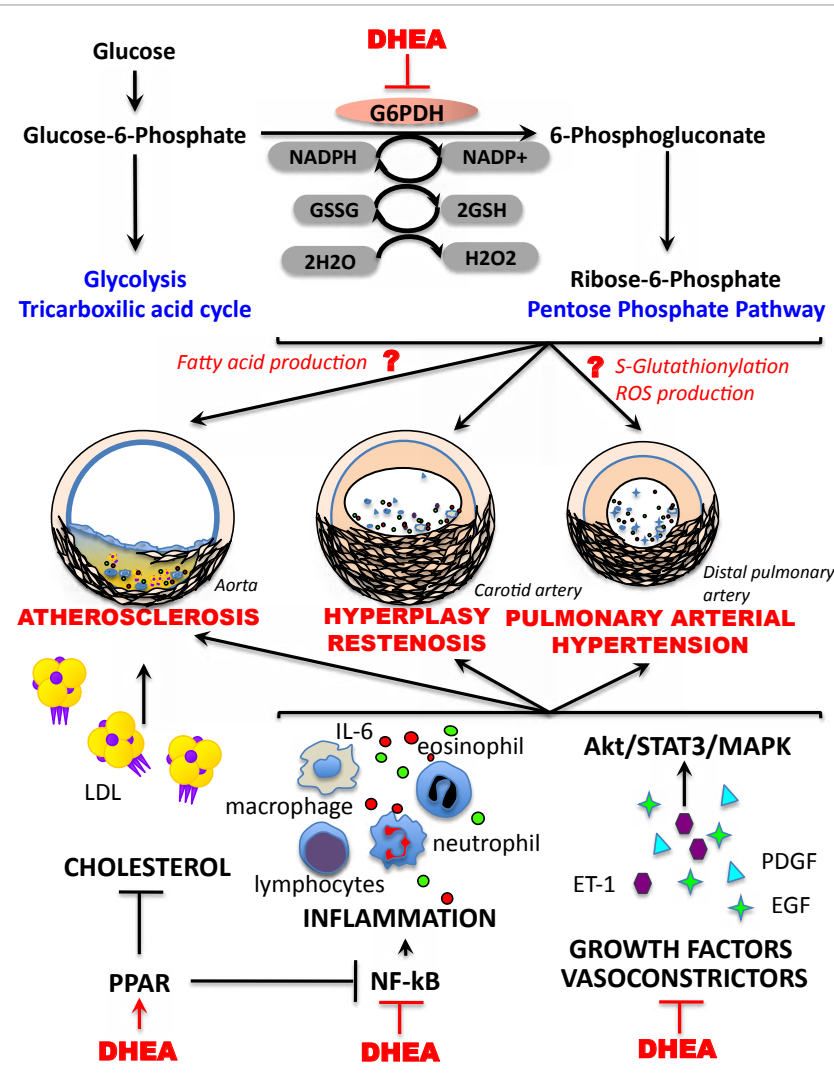

Figure 1: Vascular remodeling diseases are characterized by an inappropriate inward narrowing of the vessels that obstruct the lumen and decrease the flow. In artherosclerosis, there is an important role of "bad cholesterol" low-density lipoprotein (LDL) that once oxidized, is incorporated by leucocytes (monocytes, lymphocytes...) to form foam cells that and accumulate in the sub-endothelial space due to an impaired migration. Vascular smooth muscle cells (VSMCs) migrate into the neointima and secrete matrix proteins to stabilize the plaque. Instability in the cap may lead to rupture and subsequent thrombus formation. In hyperplasia and pulmonary arterial hypertension, the narrowing is due to increased VSMCs constriction, proliferation and survival, fulfilling the internal space. Pro-inflammatory molecules, vasoconstrictors and growth factors play a critical role in the enhancement of this inappropriate VSMCs phenotype. Dehydroepiandrosterone (DHEA), that has been described to have anticholesterol, anti-proliferative, anti-inflammatory and vasodilating properties appear to be beneficial in the treatment of vascular remodeling diseases. Nonetheless, the exact mechanism by which DHEA acts is still unclear. Several evidences suggest that DHEA is a peroxisome proliferator. Through PPAR factors activation, several genes implicated in lipid metabolism are expressed, dereasing LDL accumulation. PPARa is also implicated in inhibition of inflammation by antagonize NF-KB. Moreover PPAR factors are able to enhance the expression of genes like glutaredoxin (GRX1), playing an important role in the downregulation of tyrosine phosphorylation, like for the PDGF receptor, and glutathionylation, a post transcriptional modification that could be implicated in DHEA-dependant inhibition of signaling factors such as Akt, STAT3 and NF-kB. Originally, DHEA was described as an inhibitor of the glucose 6-phosphate deshydrogenase $(\mathrm{G} 6 \mathrm{PDH})$, whose role in vascular remodeling processes is unknown. However, G6PDH inhibition is known to change NADPH ratio, whose reduced levels lead to decreased fatty acid production and subsequent reduction of LDL production; GSH ratio, which is also implicated in protein glutathionylation; and reactive oxygen species (ROS) production implicated in enhanced vasdilatation. Thus, DHEA-dependant G6PDH inhibition could also be beneficial in the treatment of vascular remodeling diseases.

dependent protein kinase, calcineurin and spindle pole body protein

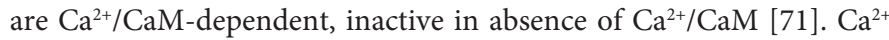
is also able to act directly on transcription factors (such as DREAM) or indirectly through protein phosphatase (calcineurin/NFAT) or kinases (CaM kinases/CREB, PKC/NFkB) to induce the activation of numerous target genes. Thus, the ability of DHEA to induce dilatation and to release cytosolic $\mathrm{Ca}^{2+}$ may also play important roles in cell proliferation. Nonetheless, DHEA is also recognized for anti-proliferative properties through its actions on pro-proliferative factors. DHEA treatment of human aortic SMC inhibits PDGF-induced MAPK activation [72]. In human internal mammary artery, DHEA significantly decreases PDGFinduced ERK1 kinase activity in a dose-dependant manner [73]. We also showed recently, in human carotid VSMC, that DHEA could inhibit PDGF induced-Akt activation [74]. These results were confirmed in vivo by a decrease of vascular remodeling in the rat model of ballooninjured carotid treated with DHEA, showing the potential of DHEA as therapeutic for restenosis. It was demonstrated that PDGF-induced proliferation is inhibited by DHEA through a GSH/GRX1 mechanism [75], GRX1 playing an important role in PDGF signal regulation by a downregulation of tyrosine phosphorylation of the PDGF receptor [76]. This is in agreement with previous findings showing that GRX1 and $\gamma$-Glutamylcysteine synthetase ( $\gamma$-GCS) display a PPAR response element in their promoter and are up-regulated at the transcriptional level by PPARa.

We have recently demonstrated the critical role of the Src/STAT3 (Signal transducer and activator of transcription 3) axis in PAH, that enhance NFAT (Nuclear Factor of Activated T-cells) expression and activation through a Pim1 (Provirus integration site for Moloney murine leukemia virus) dependant mechanism [77]. STAT3 has also been showed as a regulator of the Bone morphogenic protein receptor 2 (BMPR2) [78], which is recognized as a hallmark of PAH [79,80]. An association between DHEA treatment and decreased STAT3 activation in regenerative rat liver [81] has been previously described and make us hypothesized that DHEA could also reverse PAH by STAT3 inhibition. Indeed, we demonstrated in vitro and in vivo that DHEA treatments decrease Src/STAT3 activation in PAH and restore several STAT3downstream targets aberrantly expressed in PAH, such as BMPR2, Survivin, Pim 1 and NFATc2 [82]. Nonetheless, the mechanism by which DHEA decreases STAT3 activation remains unknown. Once again, the PPAR family of proteins could be implicated in this mechanism as it has been demonstrated that activation of PPAR $\gamma$, which is downregulated in PAH[83], have an inhibitory effect on STAT3[84-86]. A direct physical protein-protein interaction occurs between PPAR $\gamma$ and the active form of STAT3, resulting in a decreased transcriptional activity of STAT3. Moreover, the PPAR $\gamma$ agonist ciglitazone has been showed to decrease the level of STAT3 phosphorylation in glioblastoma cell lines, correlated with an increased expression of STAT3 inhibitors like the Suppressor of cytokine signaling (SOCS) 3 and the Protein inhibitor of activated STAT3 (PIAS3) [87]. PPAR $\gamma$ agonists rosiglitazone and pioglitazone that have been used in the treatment of $\mathrm{PAH}$ patients were associated with adverse cardiovascular events [88], thus DHEA may offers an alternative therapeutic approach.

\section{Discussion}

Whereas several studies have strong evidences in vitro and in vivo showing that DHEA have several beneficial effects for the treatment of vascular remodeling, DHEA is still clinically poorly used. The first reason that can explain this skepticism is in part due to controversial epidemiologic studies. Nonetheless, these studies are often performed by measurement of endogenous DHEAS, and never on DHEA directly, which is understandable considering the fact that DHEAS is the circulatory form of DHEA, more stable and no representative/ correlative to DHEA levels and variations. DHEA present diurnal variations $[89,90]$ and the metabolic clearance of DHEAS is lower than 
the DHEA one [91]. These parameters should be considered in the future in order to avoid mis-conclusion about the inverse correlation between DHEA levels and vascular remodeling diseases frequency.

Another reason is the lack of knowledge regarding the exact mechanism of action of the molecule. I think that DHEA has lost credibility by the fact that it has been considered as a "miracle drug". Moreover, the scientific community is more and more dedicated to avoid side effect of treatments, and successfully accomplish this step is easier when the implicated molecular and signaling mechanisms are well known. The skepticism was thus replaced by fear of a long-term tragic side effect. Close to 30 years after the first studies, no specific toxicity has been described for DHEA, and we are close to define the exact action of DHEA. Known as a G6PDH inhibitor, it is believe that DHEA major effects are independent of this property. DHEA synthetic analogues 8354 and 8356 , are 37 -fold and 144 -fold stronger inhibitors of G6PDH respectively than natural DHEA. However, they have less effect for example on CE accumulation, compare to natural DHEA [37]. Moreover, the role of G6PDH in vascular remodeling diseases is unclear. Some report described that G6PDH is implicated in VSMCs contractility [92-94] but it is not clearly established that this pathway is aberrantly expressed in vascular remodeling diseases. Thus, DHEA effects may not actually be related to the inhibition/rescue of G6PDH and associated pathways.

As described above, a lot of the DHEA effects can be associated to PPAR activation. PPAR $a$ has been shown to decrease fat accumulation, by enhancing enzyme involved in fat synthesis [39,40], regulates the transcription of lipolytic genes [41,42]. PPAR $\alpha$ is also implicated in inhibition of inflammation by antagonize NF- $\kappa B$ [44-48]. And finally, by enhancing the transcription of multiple genes like GRX1, PPAR $\alpha$ seems to play an important role the downregulation of tyrosine phosphorylation, like for the PDGF receptor [76]. We are now in rights to ask the tantalize question: Does this mechanism of reduced tyrosine phosphorylation can be implicated as well in the inhibition of Akt, STAT3, NF- $\kappa$ B and other transcription factor?

STAT3 is in part regulated by glutathionylation, a reversible and redox-sensitive post-translational modification occurring under oxidative stress. Glutathionylation of STAT3 decreases its affinity as a substrate for enzymatic phosphorylation and abrogates STAT3-specific DNA binding [95]. Glutathionylation depends on Glutaredoxin (GRX) and thioredoxin levels (deglutathionylation enzymes) and on the increase in the cellular GSH/GSSG ratio, which also exert a reversible action on protein S-glutathionylation. Interestingly Akt[96], NFkB [97], and other protein like eNOS or MEKK1 $[98,99]$ are also subject to glutathionylation. This mechanism of regulation may be a masterpiece in the understanding of DHEA effect as a peroxysome proliferator.

Concerning DHEA vasodilatator properties, since Src and STAT3 is known as $\mathrm{K}+$ channels inhibitors/ $\mathrm{Ca}^{2+}$ channel opener [100104] their inhibition by DHEA in PAH could explain how DHEA upregulates $\mathrm{K}_{\mathrm{v}}$ and $\mathrm{BK}_{\mathrm{Ca}}$ channels [63]. The large panel of DHEA action is probably secondary to the effect on a masterpiece like PPAR factors and repercussion of this signal downstream. Nonetheless, the implication of PPAR in all these processes is only speculative and has to be confirmed. It will be interesting that future studies dedicated to increase the knowledge on DHEA effect on vascular diseases take a look on PPAR implication.
DHEA is orally available, relatively cheap and without known side effects. Because DHEA is a naturally occurring substance, it belongs to the public domain and cannot be patented. Therefore, pharmaceutical companies are not rushing to invest millions of dollars on clinical trials to determine the effectiveness of DHEA. However, a wide range of small-scale studies has been conducted on DHEA for many years and for many diseases, and the findings show great promise for the value of DHEA. Interestingly, pharmaceutical firms have tested some synthetic forms of DHEA. With the development of the knowledge on DHEA properties, we will maybe see the development of interesting synthetic molecules that will reconcile DHEA and industry.

\section{References}

1. Heeneman S, Sluimer JC, Daemen MJ (2007) Angiotensin-converting enzyme and vascular remodeling. Circ Res 10: 441-454.

2. Parker CR (1999) Dehydroepiandrosterone and dehydroepiandrosterone sulfate production in the human adrenal during development and aging Steroids 64: 640-647.

3. Baulieu EE (2002) Androgens and aging men. Mol Cell Endocrinol 198: 41-49.

4. Bélanger A, Candas B, Dupont A, Cusan L, Diamond P, et al. (1994) Changes in serum concentrations of conjugated and unconjugated steroids in 40- to 80-year-old men. J Clin Endocrinol Metab 79: 1086-1090.

5. Labrie F, Bélanger A, Cusan L, Gomez JL, Candas B (1997) Marked decline in serum concentrations of adrenal $\mathrm{C} 19$ sex steroid precursors and conjugated androgen metabolites during aging. J Clin Endocrinol Metab 82: 2396-2402.

6. Barrett-Connor E, Khaw KT, Yen SS (1986) A prospective study of dehydroepiandrosterone sulfate, mortality, and cardiovascular disease. N Eng J Med 315: 1519-1524.

7. Schriock ED, Buffington CK, Hubert GD, Kurtz BR, Kitabchi AE, et al. (1988) Divergent correlations of circulating dehydroepiandrosterone sulfate and testosterone with insulin levels and insulin receptor binding. J Clin Endocrinol Metab 66: 1329-1331.

8. Schwartz AG, Pashko L, Whitcomb JM (1986) Inhibition of tumor development by dehydroepiandrosterone and related steroids. Toxicol Pathol 14: 357-362.

9. Casson PR, Andersen RN, Herrod HG, Stentz FB, Straughn AB, et al. (1993) Oral dehydroepiandrosterone in physiologic doses modulates immune function in postmenopausal women. Am J Obstet Gynecol 169: 1536-1539.

10. Morales AJ, Nolan JJ, Nelson JC, Yen SS (1994) Effects of replacement dose of dehydroepiandrosterone in men and women of advancing age. J Clin Endocrinol Metab 78: 1360-1367.

11. Cocco P, Todde P, Fornera S, Manca MB, Manca P, et al. (1998) Mortality in a cohort of men expressing the glucose-6-phosphate dehydrogenase deficiency. Blood 91: 706-709.

12. Gordon GB, Bush DE, Weisman HF (1988) Reduction of atherosclerosis by administration of dehydroepiandrosterone. A study in the hypercholesterolemic New Zealand white rabbit with aortic intimal injury. J Clin Invest 82: 712-720.

13. Arad Y, Badimon JJ, Badimon L, Hembree WC, Ginsberg HN (1989) Dehydroepiandrosterone feeding prevents aortic fatty streak formation and cholesterol accumulation in cholesterol-fed rabbit. Arteriosclerosis 9: 159-166.

14. Eich DM, Nestler JE, Johnson DE, Dworkin GH, Ko D, et al. (1993) Inhibition of accelerated coronary atherosclerosis with dehydroepiandrosterone in the heterotopic rabbit model of cardiac transplantation. Circulation 87: 261-269.

15. Yen SS, Morales AJ, Khorram O (1995) Replacement of DHEA in aging men and women. Potential remedial effects. Ann N Y Acad Sci 774: 128-142.

16. Weksler ME (1996) Hormone replacement for men. BMJ 312: 859-860.

17. Shomali ME (1997) The use of anti-aging hormones. Melatonin, growth hormone, testosterone, and dehydroepiandrosterone: consumer enthusiasm for unproven therapies. Md Med J 46: 181-186.

18. Barrett-Connor E, Goodman-Gruen D (1995) The epidemiology of DHEAS and cardiovascular disease. Ann N Y Acad Sci 774: 259-270. 
Citation: Paulin R, Bonnet S (2011) Dehydroepiandrosterone, Over-studied but Under-used in the Treatment of Vascular Remodeling Diseases. J Steroids Hormon Sci S3:001. doi:10.4172/2157-7536.S3-001

Page 5 of 7

19. Barrett-Connor E Goodman-Gruen D (1995) Dehydroepiandrosterone sulfate does not predict cardiovascular death in postmenopausal women. The Rancho Bernardo Study. Circulation 91: 1757-1760.

20. LaCroix AZ, Yano K, Reed DM (1992) Dehydroepiandrosterone sulfate incidence of myocardial infarction, and extent of atherosclerosis in men. Circulation 86: 1529-1535.

21. Contoreggi CS, Blackman MR, Andres R, Muller DC, Lakatta EG, et al. (1990) Plasma levels of estradiol, testosterone, and DHEAS do not predict risk of coronary artery disease in men. J Androl 11: 460-470.

22. Rocha VZ, Libby P (2009) Obesity, inflammation, and atherosclerosis. Nat Rev Cardiol 6: 399-409

23. Steinberg D (2002) Atherogenesis in perspective: hypercholesterolemia and inflammation as partners in crime. Nat Med 8: 1211-1217.

24. Aviram M, Rosenblat M, Etzioni A, Levy R (1996) Activation of NADPH oxidase required for macrophage-mediated oxidation of low-density lipoprotein. Metabolism 45: 1069-1079.

25. Marumo T, Schini-Kerth VB, Fisslthaler B, Busse R (1997) Platelet-derived growth factor-stimulated superoxide anion production modulates activation of transcription factor NF-kappaB and expression of monocyte chemoattractant protein 1 in human aortic smooth muscle cells. Circulation 96: 2361-2367.

26. Griendling KK, Sorescu D, Ushio-Fukai M (2000) NAD(P)H oxidase: role in cardiovascular biology and disease. Circ Res 86: 494-501.

27. Lusis AJ (2000) Atherosclerosis. Nature 407: 233-241.

28. Newby AC, Zaltsman AB (1999) Fibrous cap formation or destruction--the critical importance of vascular smooth muscle cell proliferation, migration and matrix formation. Cardiovasc Res 41: 345-360

29. Geng YJ, Libby P (2002) Progression of atheroma: a struggle between death and procreation. Arterioscler Thromb Vasc Biol 22: 1370-1380.

30. Nestler JE, Barlascini CO, Clore JN, Blackard WG (1988) Dehydroepiandrosterone reduces serum low density lipoprotein levels and body fat but does not alter insulin sensitivity in normal men. J Clin Endocrinol Metab 66: 57-61.

31. Cleary MP, Zabel T, Sartin JL (1988) Effects of short-term dehydroepiandrosterone treatment on serum and pancreatic insulin in Zucker rats. J Nutr 118: 382-387.

32. Cleary MP, Zisk JF (1986) Anti-obesity effect of two different levels of dehydroepiandrosterone in lean and obese middle-aged female Zucker rats. Int J Obes 10: 193-204.

33. Tagliaferro AR, Davis JR, Truchon S, Van Hamont N (1986) Effects of dehydroepiandrosterone acetate on metabolism, body weight and composition of male and female rats. J Nutr 116: 1977-1983.

34. Mohan PF, Ihnen JS, Levin BE, Cleary MP (1990) Effects of dehydroepiandrosterone treatment in rats with diet-induced obesity. J Nutr 120: 1103-1114.

35. Lopez, A, Krehl WA (1967) A possible interrelation between glucose-6phosphate dehydrogenase and dehydroepiandrosterone in obesity. Lancet 2 : 485-487.

36. Watson RR, Huls A, Araghinikuam M, Chung S (1996) Dehydroepiandrosterone and diseases of aging. Drugs Aging 9: 274-291.

37. Taniguchi S, Yanase T, Kobayashi K, Takayanagi R, Nawata H (1996) Dehydroepiandrosterone markedly inhibits the accumulation of cholesteryl ester in mouse macrophage J774-1 cells. Atherosclerosis 126: 143-154.

38. Yamada J, Sakuma M, Ikeda T, Fukuda K, Suga T (1991) Characteristics of dehydroepiandrosterone as a peroxisome proliferator. Biochim Biophys Acta 1092: 233-243

39. Tang X, Ma H, Zou S, Chen W (2007) Effects of dehydroepiandrosterone (DHEA) on hepatic lipid metabolism parameters and lipogenic gene mRNA expression in broiler chickens. Lipids 42: 1025-1033.

40. Schoonjans K, Staels B, Auwerx J (1996) Role of the peroxisome proliferator- activated receptor (PPAR) in mediating the effects of fibrates and fatty acids on gene expression. J Lipid Res 37: 907-925.

41. Schoonjans K, Staels B, Auwerx J (1996) The peroxisome proliferator activated receptors (PPARS) and their effects on lipid metabolism and adipocyte differentiation. Biochim Biophys Acta 1302: 93-109.

42. Auwerx J, Schoonjans K, Fruchart JC, Staels B (1996) Regulation of triglyceride metabolism by PPARs: fibrates and thiazolidinediones have distinct effects. $J$ Atheroscler Thromb 3: 81-89

43. Karbowska J, Kochan Z (2005) Effect of DHEA on endocrine functions of adipose tissue, the involvement of PPAR gamma. Biochem Pharmacol 70: 249-257.

44. Wang L, Hao Q, Wang YD, Wang WJ, Li DJ (2011) Protective effects of dehydroepiandrosterone on atherosclerosis in ovariectomized rabbits via alleviating inflammatory injury in endothelial cells. Atherosclerosis 214: 47-57.

45. 45 Collins T, Read MA, Neish AS, Whitley MZ, Thanos D, et al. (1995) Transcriptional regulation of endothelial cell adhesion molecules: NF-kappa B and cytokine-inducible enhancers. FASEB J 9: 899-909.

46. Delerive P, De Bosscher K, Besnard S, Vanden Berghe W, Peters JM, et al (1999) Peroxisome proliferator-activated receptor alpha negatively regulates the vascular inflammatory gene response by negative cross-talk with transcription factors NF-kappaB and AP-1. J Biol Chem 274: 32048-32054.

47. Rival Y, Benéteau N, Taillandier T, Pezet M, Dupont-Passelaigue E, et al. (2002) PPARalpha and PPARdelta activators inhibit cytokine-induced nuclear translocation of NF-kappaB and expression of VCAM-1 in EAhy926 endothelial cells. Eur J Pharmacol 435: 143-151.

48. Altman R, Motton DD, Kota RS, Rutledge JC (2008) Inhibition of vascula inflammation by dehydroepiandrosterone sulfate in human aortic endothelial cells: roles of PPARalpha and NF-kappaB. Vascul Pharmacol 48: 76-84.

49. Csiszar A, Labinskyy N, Olson S, Pinto JT, Gupte S, et al. (2009) Resveratro prevents monocrotaline-induced pulmonary hypertension in rats. Hypertension 54: 668-675.

50. Schermuly RT, Dony E, Ghofrani HA, Pullamsetti S, Savai R, et al. (2005) Reversal of experimental pulmonary hypertension by PDGF inhibition. J Clin Invest 115: 2811-2821.

51. Frasch HF, Marshall C, Marshall BE (1999) Endothelin-1 is elevated in monocrotaline pulmonary hypertension. Am J Physiol 276: 304-310.

52. Rubens C, Ewert R, Halank M, Wensel R, Orzechowski HD, et al. (2001) Big endothelin-1 and endothelin-1 plasma levels are correlated with the severity of primary pulmonary hypertension. Chest 120: 1562-1569.

53. Giaid A, Yanagisawa M, Langleben D, Michel RP, Levy R, et al. (1993) Expression of endothelin-1 in the lungs of patients with pulmonary hypertension. N Engl J Med 328: 1732-1739.

54. Stewart DJ, Kubac G, Costello KB, Cernacek P (1991) Increased plasma endothelin- 1 in the early hours of acute myocardial infarction. J Am Coll Cardiol 18: 38-43.

55. Michelakis ED, McMurtry MS, Wu XC, Dyck JR, Moudgil R, et al. (2002) Dichloroacetate, a metabolic modulator, prevents and reverses chronic hypoxic pulmonary hypertension in rats: role of increased expression and activity of voltage-gated potassium channels. Circulation 105: 244-250.

56. Bonnet S, Savineau JP, Barillot W, Dubuis E, Vandier C, et al. (2003) Role of $\mathrm{Ca}(2+)$-sensitive $\mathrm{K}(+)$ channels in the remission phase of pulmonary hypertension in chronic obstructive pulmonary diseases. Cardiovasc Res 60 : 326-336

57. Lee KT, Tan IK (1975) A general colorimetric procedure using oxidized chlorpromazine hydrochloride for the estimation of enzymes dependent on $\mathrm{NADH} / \mathrm{NAD}+$ and NADPH/NADP+ systems. Mikrochim Acta 64: 139-150.

58. Weir EK, Archer SL (1995) The mechanism of acute hypoxic pulmonary vasoconstriction: the tale of two channels. FASEB J 9: 183-189.

59. Michelakis ED, Reeve HL, Huang JM, Tolarova S, Nelson DP, et al. (1997) Potassium channel diversity in vascular smooth muscle cells. Can J Physio Pharmacol 75: 889-897. 
Citation: Paulin R, Bonnet S (2011) Dehydroepiandrosterone, Over-studied but Under-used in the Treatment of Vascular Remodeling Diseases. J Steroids Hormon Sci S3:001. doi:10.4172/2157-7536.S3-001

Page 6 of 7

60. Farrukh IS, Peng W, Orlinska U, Hoidal JR (1998) Effect of dehydroepiandrosterone on hypoxic pulmonary vasoconstriction: a $\mathrm{Ca}(2+)-$ activated K(+)-channel opener. Am J Physiol 274: 186-195.

61. Peng W, Hoidal JR, Farrukh IS (1999) Role of a novel KCa opener in regulating $\mathrm{K}+$ channels of hypoxic human pulmonary vascular cells. Am J Respir Cell Mol Biol 20: 737-745.

62. Sachin AG, Kai-Xun L, Takao O, Koichi S, Masahiko O, et al. (2002) Inhibitors of pentose phosphate pathway cause vasodilation: involvement of voltagegated potassium channels. J Pharmacol Exp Ther 301: 299-305.

63. Bonnet S, Dumas-de-La-Roque E, Bégueret H, Marthan R, Fayon M, et al. (2003) Dehydroepiandrosterone (DHEA) prevents and reverses chronic hypoxic pulmonary hypertension. Proc Natl Acad Sci U S A 100: 9488-9493.

64. Münzel T, Feil R, Mülsch A, Lohmann SM, Hofmann F, et al. (2003) Physiology and pathophysiology of vascular signaling controlled by guanosine 3',5'-cyclic monophosphate-dependent protein kinase [corrected]. Circulation 108: 2172 2183.

65. Friebe A, Koesling D (2003) Regulation of nitric oxide-sensitive guanyly cyclase. Circ Res 93: 96-105.

66. Moncada S, Higgs EA (2006) The discovery of nitric oxide and its role in vascular biology. Br J Pharmacol 147: 193-201.

67. Oka M, Karoor V, Homma N, Nagaoka T, Sakao E, et al. (2007) Dehydroepiandrosterone upregulates soluble guanylate cyclase and inhibits hypoxic pulmonary hypertension. Cardiovasc Res 74: 377-387.

68. Sato A, Sakuma I, Gutterman DD (2003) Mechanism of dilation to reactive oxygen species in human coronary arterioles. Am J Physiol Heart Circ Physiol 285: 2345-2354.

69. Fujimoto S, Asano T, Sakai M, Sakurai K, Takagi D, et al. (2001) Mechanisms of hydrogen peroxide-induced relaxation in rabbit mesenteric small artery. Eur J Pharmacol 412: 291-300.

70. Homma N, Nagaoka T, Karoor V, Imamura M, Taraseviciene-Stewart L, et al. (2008) Involvement of RhoA/Rho kinase signaling in protection against monocrotaline-induced pulmonary hypertension in pneumonectomized rats by dehydroepiandrosterone. Am J Physiol Lung Cell Mol Physiol 295: 71-78.

71. Means AR (1994) Calcium, calmodulin and cell cycle regulation. FEBS Lett 347: 1-4.

72. Yoshimata T, Yoneyama A, Jin-no Y, Tamai N, Kamiya Y (1999) Effects of dehydroepiandrosterone on mitogen-activated protein kinase in human aortic smooth muscle cells. Life Sci 65: 431-440.

73. Williams MR, Ling S, Dawood T, Hashimura K, Dai A, et al. (2002) Dehydroepiandrosterone inhibits human vascular smooth muscle cell proliferation independent of ARs and ERs. J Clin Endocrinol Metab 87: 176181.

74. Bonnet S, Paulin R, Sutendra G, Dromparis P, Roy M, et al. (2009) Dehydroepiandrosterone reverses systemic vascular remodeling through the inhibition of the Akt/GSK3-\{beta\}/NFAT axis. Circulation 120: 1231-1240.

75. Urata Y, Goto S, Kawakatsu M, Yodoi J, Eto M, et al. DHEA attenuates PDGFinduced phenotypic proliferation of vascular smooth muscle A7r5 cells through redox regulation. Biochem Biophys Res Commun 396: 489-494.

76. Kanda M, Ihara Y, Murata H, Urata Y, Kono T, et al. (2006) Glutaredoxin modulates platelet-derived growth factor-dependent cell signaling by regulating the redox status of low molecular weight protein-tyrosine phosphatase. J Bio Chem 281: 28518-28528.

77. Paulin R, Courboulin A, Meloche J, Mainguy V, Dumas de la Roque E, et al. (2011) Signal transducers and activators of transcription-3/pim1 axis plays a critical role in the pathogenesis of human pulmonary arterial hypertension. Circulation 123: 1205-1215

78. Brock M, Trenkmann M, Gay RE, Michel BA, Gay S, et al. (2009) Interleukin-6 modulates the expression of the bone morphogenic protein receptor type II through a novel STAT3-microRNA cluster $17 / 92$ pathway. Circ Res 104: 11841191.

79. Zakrzewicz A, Hecker M, Marsh LM, Kwapiszewska G, Nejman B, et al. (2007)
Receptor for activated C-kinase 1, a novel interaction partner of type II bone morphogenetic protein receptor, regulates smooth muscle cell proliferation in pulmonary arterial hypertension. Circulation 115: 2957-2968.

80. Tada Y, Majka S, Carr M, Harral J, Crona D, et al. (2007) Molecular effects of loss of BMPR2 signaling in smooth muscle in a transgenic mouse model of PAH. Am J Physiol Lung Cell Mol Physiol 292: 1556-1563.

81. Kopplow K, Wayss K, Enzmann H, Mayer D (2005) Dehydroepiandrosterone causes hyperplasia and impairs regeneration in rat liver. Int J Oncol 27: 1551 1558

82. Paulin R, Meloche J, Jacob MH, Bisserier M, Courboulin A, et al. (2011) Dehydroepiandrosterone inhibits the Src/STAT3 constitutive activation in Pulmonary Arterial Hypertension. Am J Physiol Heart Circ Physiol 301: 798809 .

83. Hansmann G, Wagner RA, Schellong S, Perez VA, Urashima T, et al. (2007) Pulmonary arterial hypertension is linked to insulin resistance and reversed by peroxisome proliferator-activated receptor-gamma activation. Circulation 115 1275-1284.

84. Wang LH, Yang XY, Zhang X, Huang J, Hou J, et al. (2004) Transcriptional inactivation of STAT3 by PPARgamma suppresses IL-6-responsive multiple myeloma cells. Immunity 20: 205-218

85. Kim HJ, Rho YH, Choi SJ, Lee YH, Cheon H, et al. (2005) 15-Deoxy-delta12,14PGJ2 inhibits IL-6-induced Stat3 phosphorylation in lymphocytes. Exp Mol Med 37: 179-185

86. Ji JD, Kim HJ, Rho YH, Choi SJ, Lee YH, et al. (2005) Inhibition of IL-10-induced STAT3 activation by 15-deoxy-Delta12,14-prostaglandin J2. Rheumatology (Oxford) 44: 983-988

87. Ehrmann J, Strakova N, Vrzalikova K, Hezova R, Kolar Z (2008) Expression of STATs and their inhibitors SOCS and PIAS in brain tumors. In vitro and in vivo study. Neoplasma 55: 482-487.

88. Juurlink DN, Gomes T, Lipscombe LL, Austin PC, Hux JE, et al. (2009) Adverse cardiovascular events during treatment with pioglitazone and rosiglitazone: population based cohort study. BMJ 339: 2942.

89. Rosenfeld RS, Hellman L, Roffwarg H, Weitzman ED, Fukushima DK, et al. (1971) Dehydroisoandrosterone is secreted episodically and synchronously with cortisol by normal man. J Clin Endocrinol Metab 33: 87-92.

90. Nieschlag E, Loriaux DL, Ruder HJ, Zucker IR, Kirschner MA, et al. (1973) The secretion of dehydroepiandrosterone and dehydroepiandrosterone sulphate in man. J Endocrinol 57: 123-134.

91. Baulieu EE (1996) Dehydroepiandrosterone (DHEA): a fountain of youth? J Clin Endocrinol Metab 81: 3147-3151.

92. Ata H, Rawat DK, Lincoln T, Gupte SA (2011) Mechanism of glucose-6phosphate dehydrogenase-mediated regulation of coronary artery contractility. Am J Physiol Heart Circ Physiol 300: 2054-2063.

93. Gupte RS, Ata H, Rawat D, Abe M, Taylor MS, et al. (2011) Glucose-6-phosphate dehydrogenase is a regulator of vascular smooth muscle contraction. Antioxid Redox Signal 14: 543-558.

94. Matsui R, Xu S, Maitland KA, Hayes A, Leopold JA, et al. (2005) Glucose-6 phosphate dehydrogenase deficiency decreases the vascular response to angiotensin II. Circulation 112: 257-263.

95. Xie Y, Kole S, Precht P, Pazin MJ, Bernier M (2009) S-glutathionylation impairs signal transducer and activator of transcription 3 activation and signaling Endocrinology 150: 1122-1131.

96. Wang J, Pan S, Berk BC (2007) Glutaredoxin mediates Akt and eNOS activation by flow in a glutathione reductase-dependent manner. Arterioscler Thromb Vasc Biol 27: 1283-1288.

97. Liao BC, Hsieh CW, Lin YC, Wung BS (2010) The glutaredoxin/glutathione system modulates NF-kappaB activity by glutathionylation of p65 in cinnamaldehyde-treated endothelial cells. Toxicol Sci 116: 151-163.

98. Chen CA, Wang TY, Varadharaj S, Reyes LA, Hemann C, et al. (2010) S-glutathionylation uncouples eNOS and regulates its cellular and vascular function. Nature 468: 1115-1118 
Citation: Paulin R, Bonnet S (2011) Dehydroepiandrosterone, Over-studied but Under-used in the Treatment of Vascular Remodeling Diseases. J Steroids Hormon Sci S3:001. doi:10.4172/2157-7536.S3-001

Page 7 of 7

99. Cross JV, Templeton DJ (2004) Oxidative stress inhibits MEKK1 by sitespecific glutathionylation in the ATP-binding domain. Biochem J 381: 675-683.

100. Nitabach MN, Llamas DA, Thompson IJ, Collins KA, Holmes TC (2002) Phosphorylation-dependent and phosphorylation-independent modes of modulation of shaker family voltage-gated potassium channels by SRC family protein tyrosine kinases. J Neurosci 22: 7913-7922.

101. Alioua A, Mahajan A, Nishimaru K, Zarei MM, Stefani E, et al. (2002) Coupling of c-Src to large conductance voltage- and $\mathrm{Ca} 2+$-activated $\mathrm{K}+$ channels as a new mechanism of agonist-induced vasoconstriction. Proc Natl Acad Sci U S A 99: 14560-14565.
102. Dey D, Shepherd A, Pachuau J, Martin-Caraballo M (2011) Leukemia inhibitory factor regulates trafficking of T-type Ca2+ channels. Am J Physiol Cell Physiol 300: 576-587.

103. Trimarchi T, Pachuau J, Shepherd A, Dey D, Martin-Caraballo M (2009) CNTF-evoked activation of JAK and ERK mediates the functional expression of T-type Ca2+ channels in chicken nodose neurons. J Neurochem 108: 246 259.

104. Hu XQ, Singh N, Mukhopadhyay D, Akbarali HI (1998) Modulation of voltagedependent $\mathrm{Ca} 2+$ channels in rabbit colonic smooth muscle cells by c-Src and focal adhesion kinase. J Biol Chem 273: 5337-5342.
This article was originally published in a special issue, Cellular Mechanism of Steroids handled by Editor(s). Dr. Tomoshige Kino, National Institutes of Health, USA 